\title{
Prevalence of Bovine Fasciolosis in Gechi District, Buno Bedelle Zone, South West Ethiopia
}

\author{
Seid Husen $^{1}$, Shimelis Girma ${ }^{1}$, Jibicho Guye ${ }^{1}$, Mengistu Geleta ${ }^{1}$ Tegenu Habebie $^{1}$, \\ Mohammad Hussen ${ }^{1}$, Mukarim Abdurahaman ${ }^{2 *}$ \\ ${ }^{1}$ Buno Bedelle zone Livestock and fisheries resource development office \\ ${ }^{2}$ Jimma University, College of Agriculture and Veterinary Medicine (JUCAVM)
}

*Corresponding Author: Mukarim Abdurahaman, Jimma University, College of Agriculture and Veterinary Medicine (JUCAVM)

\begin{abstract}
Fasciolosis is an economically important parasitic disease of cattle in Ethiopia. The aim of study was to determine the prevalence of fasciolosis in cattle A cross-sectional survey was carried out from July 2015 to October 2015 on bovine fasciolosis in Gechi district, Buno Bedlele Zone of Oromia Regional state at south western part of Ethiopia. For this, a total of 384 feacal samples were randomly collected from local breed cattle and all samples were subjected to standard sedimentation test at Animal Health laboratory of Bedele regional station; Oromia, Ethiopia. In the laboratory coproscopic examination were performed to detect the presence of Fasciola egg. Fresh fecal samples for parasitological examination were collected directly from the rectum by using disposable plastic gloves and placed in clean screw capped universal bottles. Each sample was labeled with date of submission, age, sex, body condition and place of origin (PAs). Samples were preserved with $10 \%$ formalin solution. The overall prevalence of bovine fasciolosis was found to be $23.7 \%$ from 91 positive samples. From the various risk factor analyzed, age categories of cattle, sex, body conditions and PAs influence were found to be non-significantly associated $(p>0.05)$ with the prevalence of bovine fasciolosis. When considered the relationship with sex it was observed that male $(23.40 \%)$ and female (23.97\%), in young age (23.72\%) and adult (23.68\%). As regards to body condition, poor (23.75\%) and good (23.66\%) was recorded; and the prevalence was varying among PAs that is lower $(23.07 \%)$ and higher $(24.44 \%)$ in different PAs of the study area. It can be concluded that these risk factors need to be taken in consideration when designing effective fasciolosis control management system for cattle in Ethiopia.
\end{abstract}

Keywords: Prevalence, Gechi district, Bovine, Fasciolosis.

\section{INTRODUCTION}

Livestock is an important component of farming system in Ethiopia and provides drought power milk, meat, manure, hides, skin and other products (Funk, et al., 2012).Currently the population of livestock found in Ethiopia estimated to be 55.4 million cattle, 26.5 million sheep and 23.78 million goats (CSA, 2011). Although Ethiopia has substation livestock resources level of productivity is low due to constraint of Disease. Out of these disease Fasciolosisis major disease which is imposes direct and indirect economic impact on livestock production particularly on the sheep and cattle (Keyyu et al., 2005, Menkir et al., 2007).

Bovine Fasciolosisis an economically important parasite disease of cattle caused by Fasciolidae family trematode of Genus Fasciola, the two important species of Genus, Faciola hepatica and Faciola gigantica are commonly known as liver fluke. Generally Fasciolosis is a worldwide distribution however, the distribution of Fasciola hepatica is wide spread temperate area and tropical high land of Africa (Urquhart et al., 1996).

The epidemiology of Fasciolosisis depends on the ecology of snail's intermediate host. There are many different species of lymnea but now generally agreed that two snail types are involved in the transmission of fluke, although there are species variation different countries.

In case of Fasciola hepatica the most known intermediate host Lymneatrancatula of mud snail which prefers moist temperature condition $\left(15^{\circ} \mathrm{C}-22^{\circ} \mathrm{C}\right)$, although it appears variants found in the tropic have 
adapted to higher temperature and can be breed and survive at $26^{\circ} \mathrm{C}$ with sufficient moisture during the dry season. Lymneatrancatula capable of aestivation or at least years a dry mud (Miodrag and LanMclntye, 1996).

The Intermediate host for Fasciolagigantica is of the Lymneaauricularia type. These are aquatic snail which prefers tropical or subtropical condition and thrive in well Oxygenated non polluted water. Fasciolosisis a cosmopolitans diseases and the parasite having complex life cycle involving various lymnea species amphibians and aquatic snail as an intermediate.

Infection occurs where livestock graze the habitat of snail especially in ditches marshy area. Edge of water channels flood Plains (Archi, 1994).

Fasciolosisis a serious problem in Ethiopia highland cattle raising are major to local economy (Kifle, 1998).

Apart from its veterinary and economic important throughout the world, Fasciolosishas recently been shown to be are-emerging and wide spread zoonosis affecting people (Estaban et al., 2003)

In some part of our country study conduct by Abduljabar (1992), Daniel (1995), Tolosa and Worku (1997), total economic loss showed about a total loss 154188,215000, 54063.34 Ethiopian birr per year in cattle were reported due to Fasciolosis at Ziway, Dire Dawa and Jimma Municipality slaughter houses respectively. Ilubabor is one of the potential areas in livestock Population but due to disease prevalence, the production and productivity is very low.

According to their economic importance of different animals disease that have been and still inflicting much damage to the livestock sector: Trypanosomiasis, internal parasite, infectious diseases, external parasite and commonly disease affecting cattle and other animals in the area. Among the internal parasite disease, Fasciolosis locally called 'bale' is the one which affecting cattle and other ruminants (Gechi Livestock development and Health Agency, 2015).

But, studies on the epidemiology of fasciolosis in cattle were not so far conducted in Gechi Woreda district of Oromia regional state and it was the rational that initiated this research project. Therefore, the objective of this study was:-

* To determine the prevalence of bovine fasciolosis in the study area.

\section{MATeRial AND Method}

\subsection{Study Area}

The Study was conducting from July 2015 up to end of October 2015 in buno beddelle Zone of Oromia Regional state at western part of Ethiopia in Gechi Woreda. Gechi is located at $138 \mathrm{Km}$ from Mettu town, which is the capital city of Ilu Ababora Zone, $120 \mathrm{Km}$ from Jimma town and $124 \mathrm{Km}$ from Nekemte town.

The woreda situated at latitude of $8164800 \mathrm{~N}$ and Longitude of $36341200 \mathrm{E}$ at elevation of ranging from 140- 297 m.a.s.l the study area received mean annual rain fall with an average of $1639.5 \mathrm{ml}$. the woreda has different climatic classification which includes highland (Dega) 27\%, Midland (Weyna Dega) 50\% and Lowland (Kola) 23\% and with regard land coverage, marshy area share about 2495 hectare of the total area, which is 48,652.7 hectare (Gechi woreda Agricultural Office, 2015).

\subsection{Study Population}

Study population includes local breeds of cattle; managed under traditional management system. There are a total numbers of 76,122 cattle in the Gechi woreda. From this total numbers of cattle, 384 were examined (from Chara, Haro, Mucha and Chobtu) in Gechi woreda. Totally to determine the prevalence of bovine Fasciolosis in Gechi, 384 cattle were randomly selected.

\subsection{Study Design}

The cross sectional study was designed with the objective to determine the prevalence of bovine Fasciolosis in Gechi district.

\subsection{Sample Size Determination and Sampling Method}

The animals were selected by using simple random sampling method to determine the sample size; an expected prevalence of 50\% was taken in to consideration since there was no earlier coprological 
research work on Fasciolosis in the area. Therefore, the four peasant associations (PAs), District and individual cattle in the PAs were selected by simple random sampling technique from study area (Gechi woreda). The desired sample size for the study was calculated using the formula given by Thrus field (1995) with 95\% confidence interval and at 5\% Absolute precision.

\section{$\mathrm{n}=1.96^{2} * \operatorname{Pexp}(1-\mathrm{Pexp}) / \mathrm{d}^{2}$}

Where, $n=$ required sample size

$\boldsymbol{p e x p}=$ Expected prevalence

$\boldsymbol{d}=$ Absolute precision

Totally, 384 cattle were randomly sampled in Gechi to determine the prevalence rate.

\subsection{Fecal Sample Collection and Laboratory Techniques}

In the laboratory coproscopic examination were performed to detect the presence of Fasciola egg, according to standard technique as described by Hasen and Perry (1994). Fresh fecal samples for parasitological examination were collected directly from the rectum by using disposable plastic gloves and placed in clean screw capped universal bottles. Each sample was labeled with date of submission, age, sex, body condition and place of origin (kebele). Samples were preserved with 10\% formalin solution to avoid the eggs development and hatching for laboratory diagnosis, then transported to Bedelle regional laboratory for detail coproscopic examination.

\subsection{Data Management and Analysis}

All Data generated from study were entered in to Microsoft Excel data system. The data were thoroughly screened for errors and properly coded before subjecting to statistical analysis. The Data were imported from the Microsoft excel and analyzed using STATA software 11.0 computer to determine the variation in infection prevalence in potential risk factor (Age, Sex, Pas and Body condition). Significances were considered with the "P" value less than 0.05 .

\section{RESUltS}

Out of 384 fecal sample examined an overall prevalence of 91 (23.7\%) were found positive for fasciolosis in the study area.

Table1. Coprological Prevalence of bovine Fasciolosis in Gechi District

\begin{tabular}{|c|c|c|c|c|c|}
\hline PAs & No of examined Cattle & No & Preval & P-Value & $(95 \%) \mathrm{CI}$ \\
\hline Chara & 97 & 23 & 23.71 & \multirow{5}{*}{0.886} & $0.801-1.211$ \\
\hline Haro & 90 & 22 & 24.44 & & \\
\hline Chobtu & 93 & 22 & 23.65 & & \\
\hline Mucha & 104 & 24 & 23.07 & & \\
\hline Total & 384 & 91 & 23.7 & & \\
\hline
\end{tabular}

Out of 384 cattle examined for the prevalence of bovine Fasciolosis in Gechi, 91(23.7\%) cattle were found to be positive for Fasciolosis. The higher prevalence was recorded in Haro PAs (24.44\%) and lower prevalence was in Mucha PAs (23.07). Statistical analysis showed that no significance (P > 0.05) difference between PAs.

Table2. Prevalence of bovine Fasciolosis based on age group

\begin{tabular}{|c|l|l|l|l|l|}
\hline Age & No of examined & No of Positive & Prevalence (\%) & P-Value & $(95 \%)$ CI \\
\hline Young & 118 & 28 & 23.72 & 0.999 & $0.843--1.185$ \\
\hline Adult & 266 & 63 & 23.68 & & \\
\hline Total & 384 & 91 & 23.7 & & \\
\hline
\end{tabular}

During the study period cattle were classified based on their age (1-3 years) young and (> 3 years) adult. Based on this classification of animals in Age, prevalence of bovine Fasciolosis was studied in Gechi. From 118 examined young (1-3 years) cattle about $28(23.72 \%)$ cattle was positive of Fasciolosis and among the 266 examined adult (>3 years) cattle $63(23.68 \%)$ of them were positive for Fasciolosis with an overall prevalence of $23.7 \%$. statistical analysis revealed that there is no significance difference $(\mathrm{P}>0.05)$ in prevalence between the age group (Table 4$)$. 
Table3. Prevalence of Bovine Fasciolosis based on Sex groups

\begin{tabular}{|l|l|l|l|l|l|}
\hline \multicolumn{1}{|c|}{ Sex } & No of examined & No of Positive & Prevalence (\%) & P-Value & $(95 \%)$ CI \\
\hline Male & 188 & 44 & 23.40 & 0.893 & $0.644-1.654$ \\
\hline Female & 196 & 47 & 23.97 & & \\
\hline Total & 384 & 91 & 23.7 & & \\
\hline
\end{tabular}

From the total numbers of 384 randomly selected cattle 188 of them were male, from which 44 $23.40 \%$ ) of them were positive for Fasciolosis and 196 them were female, from which 47 (23.97\%) of them were positive for Fasciolosis. Statistical analysis showed that no significance $(\mathrm{P}>0.05)$ difference in prevalence between the Sex group as indicated in the above table (table 5).

Table4. Prevalence of Bovine Fasciolosis based on body condition

\begin{tabular}{|l|l|l|l|l|l|}
\hline Body condition & No of examined & No of Positive & Prevalence $(\%)$ & P-Value & $(95 \%)$ CI \\
\hline Poor & 160 & 38 & 23.75 & 0.987 & $0.617-1.606$ \\
\hline Good & 224 & 53 & 23.66 & & \\
\hline Total & 384 & 91 & 23.7 & & \\
\hline
\end{tabular}

From 160 examined poor body condition cattle, about $38(23.75 \%)$ cattle were positive for Fasciolosis and among of 224 examined good body condition cattle $53(22.66 \%)$ of them were positive for Fasciolosis. Statistical analysis showed that no significance $(\mathrm{P}>0.05)$ difference in prevalence between body condition score. Body condition score standard indicated

\section{DISCUSSION}

The present study provides the prevalence data on bovine Fasciolosis in Gechi district. Out of 384 feacal samples analyzed $91(23.7 \%)$ found to be positive using sedimentation technique as diagnostic method. The Previous studies conducted in different part of Ethiopia by Fekadu (1988) $62.2 \%$ in Bahirdar, Yadeta (1994) 81.6\% in Ambo, Adem (1994) 56.6\% in Zeway, Rahmeto (1992) 34\% in Walliso, Yohannis (1994) 61.79\% in Gojjam and other revealed a much higher prevalence rate which disagree with the present finding 91 (23.7\%). This difference in prevalence of Fasciolosis in Ethiopia may be related with difference in ecological factor available for snail intermediate host. The occurrence of Fasciolosis in the area is influenced by a multi factorial system, which comprises, host parasite and environmental effect. In the natural foci of Fasciolosis, the Fasciola and their intermediate and final hosts form an association possessing a potential epidemiological threat (Maqbool et al., 2002).

The $23.7 \%$ prevalence of bovine Fasciolosis found in this study is agree with (22.72\%) prevalence of bovine Fasciolosis reported at Nekemte by Wassie (1995) using abattoir and less or more agrees with the previous report (24.32\%) in Mekele area (Gebretsadik et al., 2010). The likely explanation may be cattle in study area graze in the same communal grazing land with similar agro ecological condition. So that the chance of acquiring the disease or becoming of infected is similar between early released of young stock with adult.

Infection rate of bovine fasciolosis of the result of the study indicated that the prevalence of poor body condition $(23.75 \%)$ and good body condition $(23.66 \%)$ revealed that infection rate has no significant difference $(\mathrm{p}>0.05)$ on the prevalence of fasciolosis. The study done in northern Ethiopia by Solomon (2005) indicates that there is no significance difference association $(\mathrm{P}>0.05)$ between body condition of animals and this result agree with the result obtained from this study .In addition, study done by Marta (2008) indicated that there was no significance difference between age, sex and PAs and this result also agree with present study.

The prevalence of the current study in male and female animals was recorded as $23.40 \%$ and $23.97 \%$ respectively. There was non-significant difference $(\mathrm{p}>0.05)$ between the two sexes indicating that sex seems no effect on the prevalence of the disease. Similar results have been reported by Grabber and Dans (1974), Kifle (1998).This may be due to the fact that grazing of both sex groups in similar pasture.

The prevalence of the disease in different PAs of the study areas were very closely similar having chara $(23.71 \%)$, Haro $(24.44 \%)$, Chobtu (23.65\%) and Mucha $(23.07 \%)$ with non-statistical difference $(p>0.05)$ this non-significant difference indicate that there is no difference in prevalence of the disease. 
In present study, the risk of infection to all age groups was the same. The young and adult cattle have the same risk of infection similar risk of infection could be due to the fact that both young and adult cattle were forced to graze on the same pasture. This corroborates with other previous findings (Phiri et al., 2005)

Therefore, this study showed that there was no significance association $(\mathrm{P}>0.05)$ between the prevalence, with age, sex, PAs and body condition in study area.

\section{CONCLUSION AND RECOMMENDATIONS}

The present study shows that prevalence of $23.7 \%$ of bovine Fasciolosis in Buno Bedelle Zone. Therefore, it is possible to conclude that Fasciolosisis was found less prevalent in the study area, even though, the prevalence is low it should not be neglected. That means it needs attention both from livestock owners and the Veterinarian in the study area. The following few points of recommendations were forwarded

* Awareness should be created among farmers about disease transmission.

* Drainage of stagnant water in swamp areas should be carried out.

* Regular deworming program before and after the rainy season should be done.

* Finally, combinations of control measures including drainage, grazing management, and regular deworming have to be used to insure satisfactory degree of control.

\section{REFERENCES}

Abduljabar, (1992): Economic significance of Bovine Fasciolosis and Hydatidiosis in Soddo DVM thesis,Facultys veterinary medicine. Addis Ababa Universty, DebreZeit, Ethiopia.

Adem, A.(1994): Prevalence of Bovine and Ovine Fasciolosis ,a preliminary serve around Ziway region .D.V.M.Thesis,F.V.M,A.A.U, Debrezeite,Ethiopia.Pp.10.

Alemayew, R.,Tefera, W., Seble, D., Nebiyu, M., Dinka, A. and Fufa, A. (2012): Bovine Fasciolosisco prological, Abattoir survey and financial loss dou to liver condemnation in Bishoftu municipal abattoir, central Ethiopia. J, vet. Medicine animal health, Pp: 24-26.

Maqbool, A., Hayat, C.S., Alchrar, T., Hashmi, A., (2002); Epidimiology of Fasciolosis in under different managemental condition, Vet.Chiv 72,221-228.

Marta, A. (2008): prevalence of bovine Fasciolosis in selected sub cities of Addis Ababa Dairy farm. D.V.M. Thesis Jimma University.School of Veterinary Medicine. Jimma, Ethiopia.

Menkier, M., Uggla, A. and Waller, P. (2007): prevalence and seasonal incidence of nematode parasites and flukes infections of sheep and goats in eastern Ethiopia. Trop. Anim. Health prod. 39 (7): 521-531.

Miodgra, R. and LanMclntyre,D.(1996):Disease of cattle in the tropics .London Pp.531-534.

Tolosa and Worku(1997): The prevalence and economic significance Fasciolosisat Jimma, Abattoir, Ethiopia.

Wasse. M., Ephrem, B., Abdi, G. (1995): prevalence and economic loss of bovine Fasciolosis in Dessie municipal abattoir South Wollo zone, Ethiopia.Europe J. Bio.Sci, 4(2) 53-59.

Yadeta, B (1994) Epidimology of Bovine and Ovine Fasciolosis and distributions of its snail Intermediate host in western showa .Ph D thesis ,F.V.M ,A.A .U, DebreZeite 35.

Yohanis, T. (1994): bovine Fasciolosis, prevalence and economic importance assessment trail on Cattle slaughtered at Bahir Dar manisipal abattoir, D.V.M. thesis, Addis Ababa University, Faculty of Veterinary Medicine DebreZeit, Ethiopia.

Archi H., 1994.Center for Tropical veterinary medicine university of Edin burg, 2151-15.

Central statistical authority (CSA) 2011. Agriculture sample survey 2010-2011. Report on Daniel. F., (1995) Economic importance of organ condemnation due to Fasciolosisand

Ethiopia .Revenue d' elavege medicine veterinary days tropicaux.27:307-3 Fekadu, R. (1988): Ruminant Fasciolosis: study on the clinical occurrence coprology, Morphology and abattoir survey in Debre Birehan and surrounding area, M.S.C. thesis. F.V.M. A.A.U.

Funk, C., Rowland, J., Eilerts, G., kebebe, E., Biru, N., white, L, and Galu, G. (2012); Geological survey. Ramine early warning system Net-Work informing (FEWSNET).Fact sheet 3053, 6P.

Grabber, M and Dayens, P. (1974): Molluses vectors and trematodesHuman's and animals in hydatidosisin cattle and sheep slaughtered at Dire Dawa abattoir. DVM thesis faculty of veterinary Medicine, Addis Ababa University, Debrezaite, Ethiopia.

Livestock and livestock characteristics, Vol.11, statistical Bullet No. 505. Addis Ababa, Ethiopia. 
Rahmeto, A., Fufa, A., Mulgeta, B., Solomon, M., Bekele,M. and Alemayew, R.(2010):Fasciolosi prevalence, Financial losses due to liver condemnation and evaluation of a simple sedimentation diagnostic technique in cattle slaughtered at Hawasa Municipal abattoir ,Southern Ethiopia .Ethiopia Vet.J.14(1),39-51.

Gechi Livestock development and Health Agency, (2015).

Keyyu.,G.D Mon rad, J,Kyv, Gaard,NC, and Kassuku, A (2005) Epidemiology of Fasciola gigantica and Amphistomes in cattle on traditional small scale dairy and large scale dairy farm in the southern highlands of Tanzania.

Kifle A. (1998). Epidimology of Bovine Fasciolosis in Galma Auraja(Arsi) Ethiopia.Veterinary Association proceeding of the $12^{\text {th }}$ conference. Addis Ababa, Ethiopia.35-42.

Maqbool, A., Hayat, C.S., Alchrar, T., Hashmi, A., (2002); Epidimiology of Fasciolosis in under different managemental condition, Vet.Chiv 72,221-228.

Marta, A. (2008): prevalence of bovine Fasciolosis in selected sub cities of Addis Ababa Dairy farm. D.V.M. Thesis Jimma University.School of Veterinary Medicine. Jimma, Ethiopia.

Miodrag, R and LanMclntyre. 1996. Disease of cattle in the tropics. London .6.531-534.

Phiri, A.M, Phiri; I.K., Sisunge, C.S and Monrad. J.2005. prevalence of fasciolosis in Zambion cattle observed at selected abattoirs with emphasis on age, sex and origin. Journal medicine 52:414-416

Thrust field, M.(1995): Veterinary epidemiology second edition university of Edinburgh, black well science Pp. 180-188.

Tolosa and Worku (1997): The prevalence and economic significance Fasciolosisat Jimma, Abattoir, Ethiopia.

Urquhart, G., Armour, J., Duncan, Dunn, A. and Jennings, F.(1996): Veterinary Parasitology.2ed. Black Well science UK,Pp:103-113.

Yadeta, B (1994). Epidimology of Bovine and Ovine Fasciolosis and distributions of its snail Intermediate host in western show a, Ph D thesis ,F.V.M ,A.A .U, Debre Zeite pp 35.

Citation: S. Husen et al., "Prevalence of Bovine Fasciolosis in Gechi District, Buno Bedelle Zone, South West Ethiopia", International Journal of Research Studies in Biosciences (IJRSB), vol. 5, no. 12, pp. 28-33, 2018. http://dx.doi.org/10.20431/2349-0365.0512004

Copyright: (C) 2017 Authors. This is an open-access article distributed under the terms of the Creative Commons Attribution License, which permits unrestricted use, distribution, and reproduction in any medium, provided the original author and source are credited. 